\title{
Preliminary study on the influence of water level on the growth and morphology of Limnocharis flava (L.) Buchenau
}

\author{
V. P. Ranawakage, K. C. Ellawala* and G. G. Tushara Chaminda \\ Department of Civil and Environmental Engineering, Faculty of Engineering, University of Ruhuna, Hapugala, Galle, Sri Lanka
}

Received 13 June 2013; Accepted 10 September 2013

\begin{abstract}
Limnocharis flava, a species native to tropical America, is naturalized as a noxious weed in Sri Lanka, India and some other Southeast Asian countries. It is widespread in flood plains, wetlands and agricultural wetlands resulting in poor drainage. In the current study, the influence of different water conditions on growth, development and morphology of L. flava was investigated. Plants were grown on experimental pots filled with wetland soil, simulating flood, standing water and dry conditions. The highest biomass and relative growth rate was observed in the plants grown at flood conditions, while the lowest total biomass content was observed in the plants grown at dry conditions. L. flava showed morphological adaptations in different water conditions, including significant differences in the relative biomass allocation for root, petioles and leaves. Root biomass significantly increased in flooded conditions. Observed decrease in leaf area and increase in leaf total chlorophyll content may facilitate the survival in dry conditions. Plant mortality and no production of inflorescence may indicate the difficulty in surviving at dry conditions. No significant difference was observed between the plants grown under 'high flood' conditions and 'low flood' conditions. Overall, L. flava showed difficulties to grow under dry conditions, but performed well under other conditions.
\end{abstract}

Key words: Invasive / plasticity / morphology / Limnocharis flava / water conditions

\section{Introduction}

Hydrologic conditions are known to be a primary influencing factor on wetland plant communities (Kercher and Zedler, 2004). Successfully colonizing depth for a particular species varies with several factors. Depth and duration of submergence becomes one major factor, others becoming wave action, light availability and characteristics of substrate (Sorrell et al., 2002; Kercher and Zedler, 2004). After colonization, seasonal water-level fluctuations, flooding and drought occurrences may also influence species survival, composition and distribution in wetlands (Deegan et al., 2007; Li et al., 2011). As a consequence of recent urbanization and climate change, frequent flooding and drought conditions are experienced by wetland plant communities. An unfavorable result associated with this phenomenon is the loss of biodiversity in wetlands and the invasion of alien species (Kercher and Zedler, 2004). Invasive species may have traits that show high levels of plasticity, increasing their advantage in survival in different environmental gradients (Gomes and Asaeda, 2009; Zhang and Wen, 2009).

\footnotetext{
*Corresponding author: ellawala@cee.ruh.ac.lk
}

Adaptive plasticity to different and fluctuating environmental conditions may enhance the advantages of survival of invasive species over the others (Kercher and Zedler, 2004; Li et al., 2011). Most common morphological responses to flooding include shoot elongation, variations in biomass partitioning patterns and formation of aerenchyma in shoots and roots (Sultan, 2000; Macek et al., 2006). In addition, variations in parameters such as specific leaf area, relative water content (RWC) and the chlorophyll content in the tissues have been observed by different researchers (Hussner and Meyer, 2009; Li et al., 2011; Richards et al., 2011). Exposure to prolonged dry periods also affects the plant growth, morphology and development (Vasellati et al., 2001). Changing biomass partitioning patterns to increase root-shoot ratio (Asch et al., 2005), changes in the reproduction system (Rodiyati et al., 2005) and extension of roots toward the deeper soil (Dawson, 1993) or laterally (Wan et al., 1996) are some of the strategies encountered in emergent species when exposed to drought.

Limnocharis flava (Alismataceae) is an emergent, anchored, perennial aquatic herb. The species is native to tropical areas of Central and South America. They produce leaves in rosettes, thick angular petioles and 
umbel-like inflorescences with three to six flowers. The plant mainly propagates by the seeds; one fruit contains thousands of seeds (Brooks et al., 2008). In addition, vegetatively produced juveniles support the propagation (Karthigeyan et al., 2004). It is a noxious weed of wetland areas and agricultural wetlands in Sri Lanka, India, Malaysia, Indonesia and many other Southeast Asian countries (Brooks and Galway, 2006; Abhilash et al., 2008; Brooks et al., 2008). L. flava was introduced to Sri Lanka as an ornamental plant in 1898 to 'Peradeniya' botanical gardens (Abhilash et al., 2008). By 1932-1936, it had spread over the country and had almost naturalized as a serious pest in agricultural wetlands (Karthigeyan et al., 2004). Agricultural wetlands are manmade semi-aquatic ecosystems with the purpose of cultivating rice; a wide variety of hydrologic conditions is available in these areas. L. flava clogs irrigation tanks and channels, resulting in poor drainage, the abundance sometimes making the area unfit for cultivation. A thorough understanding of the biology and the ecology of the species is necessary in invasive weed management (Abhilash et al., 2008). However, such investigations on L. flava growth, survival and reproduction traits under different environmental gradients are limited so far (Brooks et al., 2008). To the best of the author's knowledge, the response of L. flava to different water levels available in agricultural wetlands has not been studied in Sri Lanka or anywhere in the world. In addition, most of the studies carried out on the responses of plants to water level have been limited to temperate climates. There are very few studies which have been carried out under tropical climatic conditions. Therefore, the objective of this study was to explore the influence of different water levels on growth, development and morphology of L. flava to characterize the probable patterns of spreading of the species in Sri Lanka and other countries in the region.

\section{Materials and Methods}

The experiment was conducted in a covered outdoor experimental facility at the Faculty of Engineering, University of Ruhuna, Galle, Sri Lanka $\left(6.08^{\circ} \mathrm{N}\right.$, $\left.80.19^{\circ} \mathrm{E}\right)$. The temperature was $28 \pm 2{ }^{\circ} \mathrm{C}$ and the plants were grown in ambient light. The plants and the substrate for plant growth were obtained from a nearby agricultural wetland (TN, $1.69 \pm 0.17 \mathrm{mg} . \mathrm{g}^{-1}$ dry weight of soil; TP, $0.01 \pm 0.004 \mathrm{mg} . \mathrm{g}^{-1}$ dry weight of soil). No additional nutrients were added during the experiment. Tap water was used for the study. Twenty-eight young, well-grown and healthy plants $(25-30 \mathrm{~cm}$ in height $)$ with same morphologies were selected for the experiment. Total fresh weight (FW) of a plant at the beginning was $21.66 \pm 8.73 \mathrm{~g}$, which did not significantly vary among plants (ANOVA, $P>0.05$ ). None had produced inflorescence at the beginning of the experiment. They were allowed to grow in the experimental pots (one plant in each pot) for 2 weeks prior to the start of experiments. Four pots were used for initial measurements, while the rest were randomly assigned for experimental treatments. One experimental treatment unit consisted of a $60-\mathrm{L}$ plastic container with three plastic nursery pots inside (diameter: $15 \mathrm{~cm}$, height: $17 \mathrm{~cm}$ ). The experiment was conducted in duplicate. Two setups (six pots) received same water conditions. The positions of the pots and the containers were randomized weekly throughout the experiment.

\section{Experimental conditions}

The plants received the following treatments: (1) flooded with $11 \mathrm{~cm}$ of water above the soil surface (hereafter called the "high flood" treatment); (2) flooded with $6 \mathrm{~cm}$ of water above the soil surface (hereafter called the "low flood" treatment); (3) watered constantly from bottom, in addition added $100 \mathrm{ml}$ of water daily per each pot (no water on top of the soil surface after $30 \mathrm{~min}$ of watering) (hereafter called the "standing water" treatment); (4) no water inside the plastic container, added $100 \mathrm{~mL}$ of water per each pot once in 3 days. In addition, once in every 21 days, pots were watered from bottom for 3 days to simulate occasional rains (hereafter called the "dry" treatment). Experimental conditions provided under different treatments are depicted in Figure 1. The study was conducted for a period of 72 days.

\section{Harvest and measurement}

Plant harvesting was carried out at the end of the experiment period. The plants were gently washed, blotted dry and weighed for total FW. Plant height and root length was measured to the nearest millimeter. Area of each leaf in each plant was recorded manually by placing the leaves on the graph sheets. Then, plants were divided into leaves, petioles, inflorescence and roots. FW of each component was measured separately and allowed to dry in an oven at $70^{\circ} \mathrm{C}$ for $72 \mathrm{~h}$. The dry weight (DW) of each part was measured separately.

\section{Relative growth rate (RGR)}

Relative growth rate was calculated as,

$$
\mathrm{RGR}=\operatorname{Ln}\left(\mathrm{DW}_{f}\right)-\operatorname{Ln}\left(\mathrm{DW}_{i}\right) / t
$$

where $\mathrm{DW}_{f}$ is the average dry weight of a plant subjected to any treatment at the end of the experiment period (72 days), $\mathrm{DW}_{i}$ is the average dry weight of a plant at the beginning of the experiment, and $t$ is time in days (Hunt, 1982). Average DW of a plant at the beginning of the experiment was determined by using four plants harvested at the beginning of the experiment.

\section{Specific leaf area (SLA) and RWC}

Specific leaf area was calculated as SLA = Leaf area/ Leaf DW. Sum of the leaf area of all leaves available in 

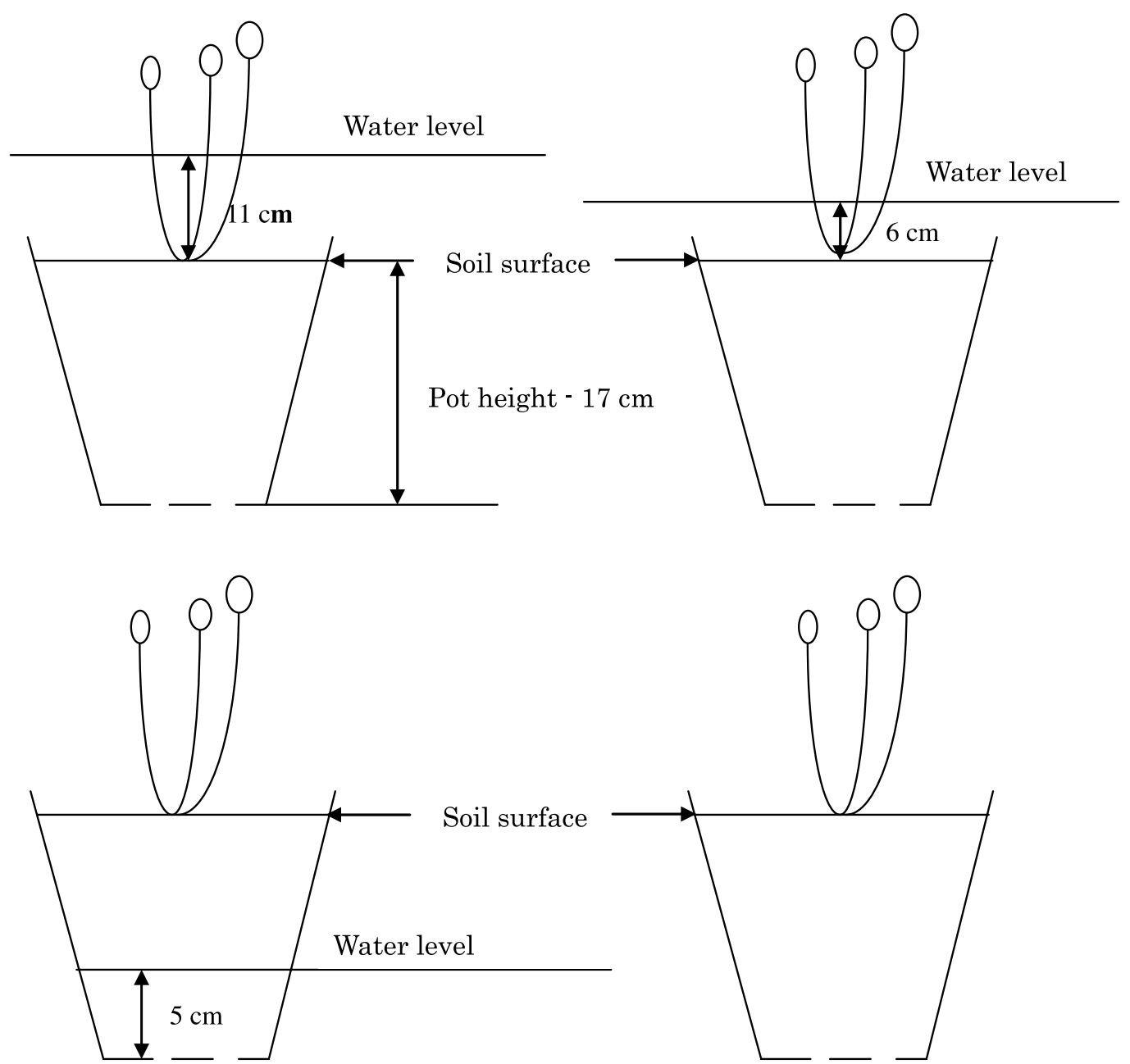

Fig. 1. Experimental conditions employed at each treatment. Water level is measured relative to the soil surface. Nursery pots were placed inside $60 \mathrm{~L}$ plastic containers.

one plant was considered as leaf area of the respective plant and the DW of all leaves was considered as leaf DW in the above calculation. Relative water content of the above ground biomass was computed using the formula RWC $\%=(F W-D W) * 100 / D W$ (Hussner and Meyer, 2009).

\section{Total chlorophyll measurements}

Leaf total chlorophyll content was determined by extracting chlorophyll in $80 \%$ acetone. Total chlorophyll concentration in the extract was measured by using a spectrophotometer (UV 1601 PC, Shimadzu, Japan) and published coefficients were used for calculation (Porra, 2002).

\section{Level of response}

The level of response of each parameter to the variation of water level was estimated by the index of response
(Response ( $_{\text {water }}$ ). Response water $_{\text {was }}$ calculated as the difference between the maximum and the minimum mean values, divided by the maximum mean value (Quero et al., 2006; Zhang and Wen, 2009). Some authors call this index as the plasticity index (Valladares et al., 2000).

\section{Statistical analysis}

All data are presented as mean \pm SD. The KolmogrovSmirnov test and Levene's check for equality of variances were performed on the data sets prior to the statistical analysis to verify the assumptions of normal distribution and homogeneity of variances. One-way ANOVA was used to check for significant differences among the plants exposed to different water levels at the end of the experimental period. Significant differences among the groups were analyzed with a post hoc Tukey test. For all these analyses, the SPSS statistical software package for Windows (Release 13, SPSS INC., Chicago, IL, USA) was used. 
Table 1. Plant height, total biomass, specific leaf area, average leaf area, leaf total chlorophyll content, root length, root-shoot ratio, relative water content, number of flowering plants and plant mortality under different water conditions and their Response ${ }_{\text {water. }}$

\begin{tabular}{|c|c|c|c|c|c|}
\hline & High flood & Low flood & Standing water & Dry & Response $_{\text {water }}$ \\
\hline$\overline{\text { Plant height }(\mathrm{cm})}$ & $39.9 \pm 1.9^{\mathrm{a}}$ & $36.1 \pm 2.6^{\mathrm{a}}$ & $34.3 \pm 2.9^{b}$ & $27.7 \pm 8.2^{\mathrm{c}}$ & 0.306 \\
\hline Total biomass (g DW) & $9.63 \pm 3.05^{\mathrm{a}}$ & $9.05 \pm 2.99^{\mathrm{a}}$ & $3.22 \pm 0.77^{b}$ & $1.49 \pm 0.21^{b}$ & 0.845 \\
\hline Specific leaf area $\left(\mathrm{cm}^{2} \mathrm{~g}^{-1} \mathrm{DW}\right)$ & $300.5 \pm 41.7^{\mathrm{a}}$ & $289.4 \pm 39.8^{\mathrm{a}}$ & $374.9 \pm 30.4^{\mathrm{b}}$ & $328.9 \pm 64.1^{\mathrm{b}}$ & 0.228 \\
\hline Average leaf area $\left(\mathrm{cm}^{2}\right)$ & $59.1 \pm 11.5^{\mathrm{a}}$ & $58.7 \pm 17.2^{\mathrm{a}}$ & $52.2 \pm 9.2^{\mathrm{b}}$ & $29.0 \pm 4.8^{b}$ & 0.509 \\
\hline Leaf total chlorophyll content (mg.g $\left.{ }^{-1} \mathrm{DW}\right)$ & $0.53 \pm 0.21^{\mathrm{a}}$ & $1.26 \pm 0.28^{\mathrm{ab}}$ & $1.04 \pm 0.35^{\mathrm{b}}$ & $1.66 \pm 0.25^{\mathrm{c}}$ & 0.692 \\
\hline Root length $(\mathrm{cm})$ & $36.6 \pm 12.5^{\mathrm{a}}$ & $29.1 \pm 3.3^{\mathrm{ab}}$ & $27.1 \pm 7.1^{\mathrm{b}}$ & $17.3 \pm 3.6^{\mathrm{c}}$ & 0.527 \\
\hline Root-shoot ratio $(\% \mathrm{DW})$ & $3.3 \pm 1.3^{\mathrm{a}}$ & $3.0 \pm 0.5^{\mathrm{a}}$ & $1.0 \pm 0.5^{\mathrm{b}}$ & $0.6 \pm 0.3^{\mathrm{b}}$ & 0.819 \\
\hline $\begin{array}{l}\text { Relative water content (\% DW) } \\
\text { (Based on above-ground biomass) }\end{array}$ & $966.6 \pm 106.2^{\mathrm{a}}$ & $1025.7 \pm 117.1^{\mathrm{a}}$ & $998.1 \pm 68.5^{\mathrm{a}}$ & $869.5 \pm 119.4^{\mathrm{b}}$ & 0.152 \\
\hline No. of flowering plants & 3 & 2 & 3 & 0 & - \\
\hline Mortality (no. of plants) & 0 & 0 & 0 & 2 & - \\
\hline
\end{tabular}

The mean $\pm \mathrm{SD}(n=6)$ of the data are shown. Means in the same row with different superscript letters are significantly different $(P<0.05)$.

\section{Results}

L. flava showed clear adaptations to four experimental conditions. Plants grown at flooded conditions showed a significantly higher total biomass content (ANOVA, $\left.F_{(3,20)}=17.060, \quad P<0.001\right) \quad($ Table 1) compared with plants grown at standing water conditions and dry conditions $(P<0.002)$. Maximum total biomass content, $9.63 \pm 3.05 \mathrm{~g} \mathrm{DW}$, was observed in high flood conditions and minimum, $1.49 \pm 0.21 \mathrm{~g} \mathrm{DW}$, was observed in dry conditions. Total biomass content of a plant grown under dry conditions was $84.5 \%$ less compared with the average total biomass content of a plant grown under high flood conditions. RWC of the plants grown in dry conditions was relatively lower (ANOVA, $F_{(3,20)}=5.163, P<0.01$ ) compared with plants grown under other conditions $(P<0.02)$ (Table 1$)$. RGR of the plants grown in different water conditions were significantly different (ANOVA, $\left.F_{(3,20)}=10.967, \quad P<0.001\right)$, while RGR of the plants grown in dry conditions was $66 \%$ less compared to the plants grown in high flood treatment. Plants grown under standing water conditions and flooded conditions had significantly high RGR compared with the plants grown under dry conditions $(P<0.001)$ (Fig. 2). It should be noted that RGR did not significantly vary between the plants grown at two different flooded conditions $(P>0.05)$. Response water $_{\text {in }} \mathrm{RGR}$ was calculated to be 0.679 .

L. flava developed phenotypic plastic adaptations when they are grown under different water conditions. Plant height was significantly less when water availability was less $\left(\mathrm{ANOVA}, F_{(3,20)}=13.986, P<0.001\right)$. Plants grown in dry conditions showed significantly low height compared with others $(P<0.02)$. The average height of a plant grown in dry conditions was $30 \%$ less compared with the average height of a plant grown in high flood conditions. Plants grown in high flood conditions showed a significant increase in root length (ANOVA, $F_{(3,20)}=4.805$, $P<0.013)$ and root biomass compared with plants grown under standing water conditions and dry conditions (ANOVA, $\left.F_{(3,20)}=15.296, P<0.001\right)$ (Table 1).

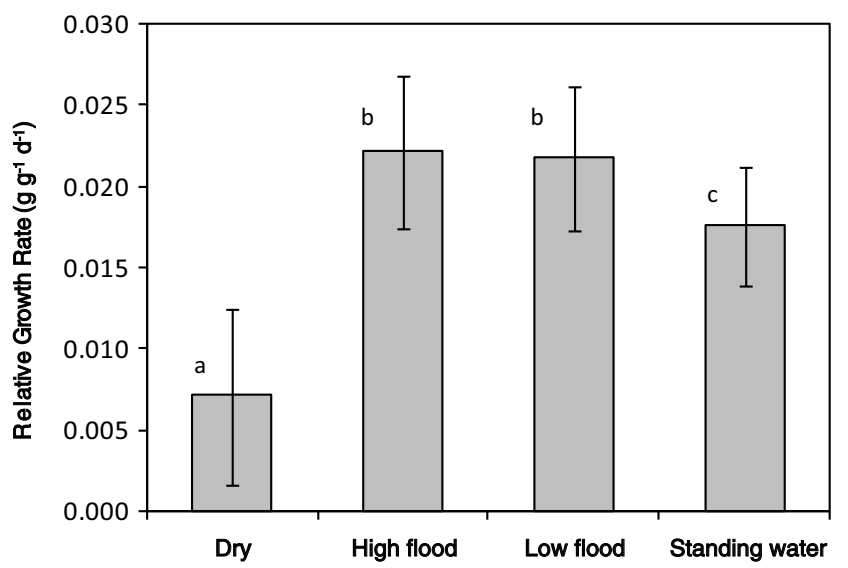

Fig. 2. Relative growth rate of Limnocharis flava grown at different water conditions (The mean $\pm \mathrm{SD}(n=6)$ of the data are shown, and the vertical bars denote the SD. Letters denote significant differences between means $(P<0.05))$.

Root-shoot ratio also showed the same pattern as root biomass (ANOVA, $F_{(3,20)}=13.428, P<0.001$ ). Dry conditions reduced the root-shoot ratio by $85 \%$ and the maximum value was observed in the plants exposed to high flood conditions (Table 1). Relative biomass amount of leaves (ANOVA, $F_{(3,20)}=49.504, P<0.001$ ) and petioles (ANOVA, $F_{(3,20)}=16.296, P<0.001$ ) were significantly lower while the relative biomass amount of roots was significantly higher (ANOVA, $F_{(3,20)}=24.270$, $P<0.001)$ at flooded conditions compared with the dry and standing water conditions $(P<0.001)$ (Fig. 3).

Plant leaf area significantly decreased with water availability (ANOVA, $F_{(3,20)}=4.646, P<0.015$ ). Further, SLA also showed significant differences among the plants grown at different water conditions (ANOVA, $F_{(3,20)}=5.012, P<0.01$ ) (Table 1$)$. Initially average leaf area of a plant was $52.9 \pm 14.0 \mathrm{~cm}^{2}$. Newly emerged leaves showed a reduction in the leaf area when they were grown at dry conditions, hence there was a reduction in the average leaf area at the end of the experiment period compared to beginning of the experiment. Reduction of 


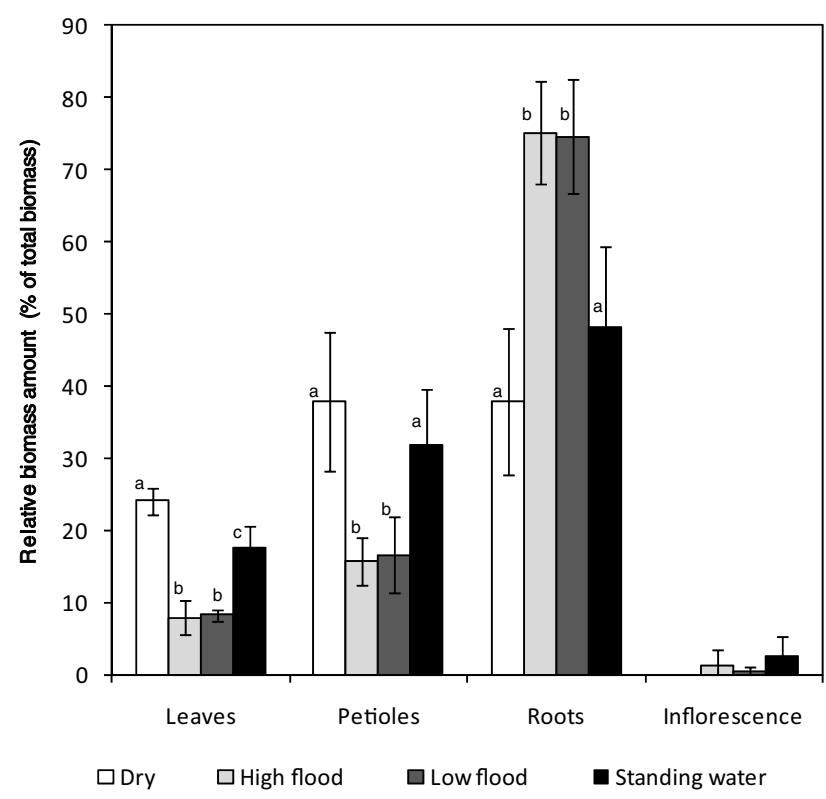

Fig. 3. Relative biomass allocation of Limnocharis flava at different water conditions, at the end of the experiment period (The mean $\pm \mathrm{SD}(n=6)$ of the data are shown, and the vertical bars denote the SD. Letters denote significant differences between means $(P<0.05))$.

the average area of a leaf was $51 \%$ when the plants were exposed to dry conditions, compared with the plants exposed to high flood conditions. However, highest leaf total chlorophyll content was observed in the plants grown in dry conditions (ANOVA, $F_{(3,20)}=5.266, P<0.027$ ) $(P<0.05)$, while the lowest was observed in the plants grown under high flood conditions $(P<0.03)$.

Response $_{\text {water }}$ in plant height, SLA and RWC was less than 0.5 , while it was higher than 0.5 for all the other parameters measured, indicating that L. flava shows plastic responses in many parameters. Plants grown in dry conditions showed no production of inflorescence, while the plants grown in other conditions showed inflorescence production. Moreover, plant mortality was observed under dry conditions only. All the plants survived under other treatment conditions.

\section{Discussion}

L. flava is an aquatic plant alien to Sri Lanka and other countries in the region. L. flava invasion in agricultural wetlands exists as a mono-species colonization which covers the whole area with time, outcompeting other species available in the area. Usually, invasive alien species are more tolerant to environmental stresses than the native species (Burns, 2004; Zhang and Wen, 2009) and show greater phenotypic plasticity compared with the native species (Davidson et al., 2011). L. flava rapidly spreads in wetlands and agricultural wetlands. This study is aimed to characterize the probable spreading patterns of this species in Sri Lanka, India and other Southeast Asian countries having same climatic conditions. Therefore, the experimental conditions for this study were selected for simulating four water levels usually available in wetlands and agricultural wetlands in Sri Lanka, in which the invasion of L. flava is a serious threat on their functioning. "High flood" and "low flood" conditions chosen for the study are common in Sri Lankan agricultural wetlands in monsoon rain periods, while "standing water" condition is available in inter-monsoon rain periods. "Dry" conditions were selected for simulating prolonged drought periods with occasional rains.

In this study, L. flava responded to the reduced water availability by producing less biomass, which is a common phenomenon observed in other wetland species also (Hussner and Meyer, 2009). Increase in relative biomass allocation for root and root-shoot ratio at flooded conditions indicates that they are employing the escaping strategy at submersion (Sultan, 2000). Adventitious root development helps them to escape root zone anoxic conditions at submersion, which is a common strategy observed in wetlands plant species (Kercher and Zedler, 2004; Jackson et al., 2009). Upward growing roots, same as those observed in Ludwigia (Ellmore, 1981), were observed in L. flava in our study. According to Ellmore (1981), such adventitious roots in aquatic plants are derived from primary cortex rather than a secondary meristem. Furthermore, Ellmore (1981) suggests that this may reflect a general difference between plants that normally grow in aquatic environments and flood-tolerant species.

Relative biomass allocation for leaves and petioles was higher at low water conditions. In contrast, leaf area was less at low water conditions. Reduction in leaf area may be an effective adaptation mechanism to low water availability since it reduces the water loss by transpiration (Li et al., 2011). In addition, higher chlorophyll density in dry conditions may encourage survival by increasing the rate of photosynthesis, though the leaf area is less. Variations were observed in relative biomass allocation, reproduction traits and RWC among different water levels. Wetland plants show this type of adaptations when they are exposed to different water conditions (Kercher and Zedler, 2004; Hussner and Meyer, 2009; Li et al., 2011).

The results of this study indicate that L. flava is able to grow at flooded and standing water conditions, successfully changing their phenotype; however, they find difficulties in survival when exposed to dry conditions. Plants produced inflorescence at all experimental conditions other than dry conditions. Low RGR, plant mortality and no reproduction under dry conditions may be considered as the signs of difficulty in survival under dry conditions. It should be noted that there were no significant differences observed between the plants grown under high and low flood conditions. Therefore, it can be hypothesized that L. flava may not be sensitive to the water level but is sensitive to the water availability. They successfully grow on flooded and saturated soils, though they are not competent in growing under dry 
weather conditions. The response of native species to the above-mentioned water levels has never been studied under Sri Lankan conditions. A comparison of the plastic behavior of $L$. flava with one of the native species may explain more about the invasive characteristics of L. flava, hence further research in this area is recommended.

Acknowledgements. This research was financially supported by the project 'Transformation of University of Ruhuna to International Status' (RU/DVC/Pro138). The authors thank Mr V. Nandadasa and Ms D. A. M. Nimal Shanthi for their support extended in experimental setup preparation and analysis.

\section{References}

Abhilash P.C., Singh N., Sylas V.P., Kumar B.A., Mathew J.C., Satheesh R. and Thomas A.P., 2008. Eco-distribution mapping of invasive weed Limnocharis flava (1.) Buchenau using geographical information system: implications for containment and integrated weed management for ecosystem conservation. Taiwania, 53, 30-41.

Asch F., Dingkuhn M., Sow A. and Audebert A., 2005. Droughtinduced change in rooting patterns and assimilate partitioning between root and shoot in upland rice. Field Crop Res., 93, 223-236.

Brooks S.J. and Galway K.E., 2006. Progress towards the eradication of two tropical weeds. Fifteenth Australian Weeds Conference, 641-644.

Brooks S.J., Weber J.M., Setter S.D. and Akacich B.A., 2008. Seed production and maturation of Limnocharis flava (1.) Buchenau in the field and glasshouse. Sixteenth Australian Weeds Conference, 180-182.

Burns J.H., 2004. A comparison of invasive and noninvasive dayflowers (Commelinaceae) across experimental nutrient and water gradients. Diversity Distrib., 10, 387-397.

Davidson A.M., Jennions M. and Nicotra A.B., 2011. Do invasive species show higher phenotypic plasticity than native species and, if so, is it adaptive? A meta-analysis. Ecol. Lett., 14, 419-431.

Dawson T.E., 1993. Hydraulic lift and water use by plants: implications for water balance, performance and plant-plant interactions. Oecologia, 95, 565-574.

Deegan B.M., White S.D. and Ganf G.G., 2007. The influence of water level fluctuations on the growth of four emergent macrophyte species. Aquat. Bot., 86, 309-315.

Ellmore G.S., 1981. Root dimorphism in Ludwigia peploides (Onargraceae): structure and gas content of mature roots. Am. J. Bot., 68, 557-568.

Gomes P.I.A. and Asaeda T., 2009. Spatial and temporal heterogeneity of Eragrostis curvula in the downstream flood meadow of a regulated river. Ann. Limnol., Int. J. Lim., 45, 181-193.

Hunt R., 1982. Plant growth curves: The functional approach to plant growth analysis, Edward Arnold Ltd., London.
Hussner A. and Meyer C., 2009. The influence of water level on the growth and photosynthesis of Hydrocotyle ranunculoides 1. Fil. Flora, 204, 755-761.

Jackson M.B., Ishizawa K. and Ito O., 2009. Evolution and mechanisms of plant tolerance to flooding stress. Ann. Bot., 103, 137-142.

Karthigeyan K., Sumathi R., Jayanthi J., Diwakar P.G. and Lakra G.S., 2004. Limnocharis flava (L.) Buchenau (Alismataceae) - a little known and troublesome weed in Andaman islands. Curr. Sci., 87, 140-141.

Kercher S.M. and Zedler J.B., 2004. Flood tolerance in wetland angiosperms: a comparison of invasive and noninvasive species. Aquat. Bot., 80, 89-102.

Li Z., Yu D. and Xu J., 2011. Adaptation to water level variation: responses of a floating-leaved macrophyte Nymphoides peltata to terrestrial habitats. Ann. Limnol. - Int. J. Lim., 47, 97-102.

Macek P., RejmáNková E.K. and Houdková K.I., 2006. The effect of long-term submergence on functional properties of Eleocharis cellulosa torr. Aquat. Bot., 84, 251-258.

Porra R.J., 2002. The chequered history of the development and use of simultaneous equations for the accurate determination of chlorophylls a and b. Photosynth. Res., 73, 149-156.

Quero J.L., Villar R., Marañón T. and Zamora R., 2006. Interactions of drought and shade effects on seedlings of four Quercus species: physiological and structural leaf responses. New Phytol., 170, 819-834.

Richards J.H., Troxler T.G., Lee D.W. and Zimmerman M.S., 2011. Experimental determination of effects of water depth on Nymphaea odorata growth, morphology and biomass allocation. Aquat. Bot., 95, 9-16.

Rodiyati A., Arisoesilaningsih E., Isagi Y. and Nakagoshi N., 2005. Responses of Cyperus brevifolius (Rottb.) Hassak. and Cyperus kyllingia Endl. to varying soil water availability. Env. Exp. Bot., 53, 259-269.

Sorrell B.K., Tanner C.C. and Sukias J.P.S., 2002. Effects of water depth and substrate on growth and morphology of Eleocharis sphacelata: implications for culm support and internal gas transport. Aquat. Bot., 73, 93-106.

Sultan S.E., 2000. Phenotypic plasticity for plant development, function and life history. Trends Plant Sci., 5, 537-542.

Valladares F., Martinez-Ferri E., Balaguer L., Perez-Corona E. and Manrique E., 2000. Low leaf-level response to light and nutrients in Mediterranean evergreen oaks: a conservative resource-use strategy? New Phytol., 148, 79-91.

Vasellati V., Oesterheld M., Medan D. and Loreti J., 2001. Effects of flooding and drought on the anatomy of Paspalum dilatatum. Ann. Bot., 88, 355-360.

Wan C., Sosebee R.E. and Mcmichael B.L., 1996. Lateral root development and hydraulic conductance in four populations of Gutierrezia sarothrae. Env. Exp. Bot., 36, 157-165.

Zhang L.-L. and Wen D.-Z., 2009. Structural and physiological responses of two invasive weeds, Mikania micrantha and Chromolaena odorata, to contrasting light and soil water conditions. J. Plant Res., 122, 69-79. 